\title{
Padrões de deslocamento e captura de forragem por novilhos em pastagem de azevém-anual e aveia-preta manejada sob diferentes alturas em sistema de integração lavoura-pecuária ${ }^{1}$
}

\author{
Carolina Baggio ${ }^{2}$, Paulo César de Faccio Carvalho ${ }^{3}$, Jamir Luís Silva da Silva ${ }^{3}$, Ibanor \\ Anghinoni $^{4}$, Marília Lazzarotto Terra Lopes ${ }^{2}$, Juliana Muliterno Thurow ${ }^{2}$ \\ ${ }^{1}$ Pesquisa financiada pelo CNPq. \\ 2 Programa de Pós-graduação em Zootecnia/UFRGS, Departamento de Plantas Forrageiras e Agrometeorologia, Cx. Postal 776, CEP: $91501-970$, \\ Porto Alegre, RS. \\ 3 Departamento de Plantas Forrageiras e Agrometeorologia da UFRGS. \\ ${ }^{4}$ Departamento de Solos da UFRGS.
}

RESUMO - Neste estudo avaliaram-se estratégias alimentares de novilhos em pastagem de azevém-anual (Lolium multiflorum Lam.) e aveia-preta (Avena strigosa Schreb.) em quatro alturas de manejo (10, 20, $30 \mathrm{e} 40 \mathrm{~cm})$ para investigar se as alturas do pasto podem influenciar os padrões de deslocamento e captura da forragem por animais em pastejo e seus impactos em sistemas de integração lavoura-pecuária. As alturas de manejo foram avaliadas em delineamento de blocos completos casualisados com três repetições. Procedeu-se a três avaliações diurnas, por observação visual direta: duas avaliações de acordo com o estádio vegetativo e a terceira com o estádio reprodutivo. A redução da altura de manejo do pasto esteve relacionada a maior carga animal e resultou em menor massa de forragem e massa de lâminas foliares. Nessa condição de limitação, os animais aumentaram a taxa de bocados, o número de bocado por estação alimentar, o número total de bocados, o número de estação alimentar visitada e reduziram o tempo de permanência na estação alimentar. Esse padrão de resposta resultou em menor deslocamento entre estações alimentares, no entanto, a quantidade de deslocamento total foi maior. Os animais modificam seus padrões de deslocamento e captura de forragem em resposta à altura de manejo do pasto. A limitação de forragem pode ter impacto no sistema de integração lavoura-pecuária.

Palavras-chave: bocado, bovinos, deslocamento, estações alimentares

\section{Displacement patterns and herbage capture by steers in Italian ryegrass and Black oat pastures managed under different heights in integrated crop-livestock system}

\begin{abstract}
This experiment was aimed to evaluate the grazing strategies of steers in Italian ryegrass (Lolium multiflorum Lam.) and black oat (Avena strigosa Schreb.) pastures managed with four sward heights, 10, 20, 30 and $40 \mathrm{~cm}$. The hypothesis that different sward heights could determine variations on the displacement patterns and herbage capture by grazing animals, with potential impacts in a crop-livestock system was tested. The treatments (sward heights) were distributed in a randomized block design with three replicates. Diurnal evaluations were performed by visual assessment in three periods, two of them in the vegetative stage and the one in the reproductive stage. Results indicated that decreases in the sward height were related to the increased stocking rate, resulting in lower herbage mass and leaf blade mass. In this limited condition, animals increased the bite rate, the number of bites per feeding station, the total number of bites, the number of visited feeding stations and decreased the time spent per feeding station. This response pattern resulted in lower displacement among feeding stations; however, the total displacement observed was greater. The animals changed their herbage capture and displacement patterns in response to sward heights, where limited herbage availability could impact the crop-livestock system.
\end{abstract}

Key Words: bite, displacement, feeding station, steers

\section{Introdução}

Sistemas de integração lavoura-pecuária têm efeito do animal e esse efeito depende, entre outros, do manejo da intensidade de pastejo, principal determinante da produção animal, das condições de soloe da quantidade de palhada que se transferem à fase agrícola (Carvalho et al., 2005). Isso porque a presença do animal têm influencia nas

Este artigo foi recebido em 17/8/2007 e aprovado em 31/7/2008.

Correspondências devem ser enviadas para: cbaggio4@terra.com.br 
propriedades físicas do solo, portanto, dependendo da taxa de lotação utilizada, é necessária a compactação do solo (Carvalho et al., 2005).

Conte et al. (2007) demonstraram que o aumento da intensidade de pastejo em pastagens de inverno aumenta a resistência do solo à penetração, no entanto, a presença do animal não significa, necessariamente, comprometimento do sistema. Pastagens de inverno conduzidas em intensidades moderadas, entre 15-20 até $30 \mathrm{~cm}$ de altura, possibilitam aumentar o desempenho animal, a eficiência do processo de pastejo, a cobertura do solo e o acúmulo de carbono sem reduzir a quantidade de grãos da lavoura subseqüente (Carvalho et al., 2005).

Herbívoros - por meio do seu comportamento em pastejo - têm importante papel regulador no equilíbrio do sistema. Esse comportamento se caracteriza pelo tempo de procura por estações alimentares, pelo tempo de permanência na estação alimentar, pelo número de bocados e pela duração do bocado na estação alimentar (Stuth, 1991). Assim, ao escolher a estação alimentar, o animal permanece nela até que o consumo de nutrientes diminua a quantidades inferiores à média pré-experimentada, considerando todo o ambiente alimentar (Carvalho \& Moraes, 2005), quando se deslocam em busca de novos locais de alimentação para garantir melhor consumo de nutrientes (Roguet et al., 1998).

A importância e aplicação desses conceitos do processo de pastejo em sistemas integrados de lavoura-pecuária baseiam-se na hipótese de que o manejo do pasto, ao determinar maior ou menor deslocamento de animais na área, dependendo da quantidade de massa de forragem, afeta as características físicas do solo e a lavoura em sucessão. Este estudo foi realizado para investigar os padrões de deslocamento e de captura de forragem de novilhos em pasto com diferentes alturas e estádios fenológicos.

\section{Material e Métodos}

O experimento foi realizado no período de julho a novembro de 2005, na Fazenda do Espinilho, situada no município de Tupanciretã, região fisiográfica do Planalto Médio do Rio Grande do Sul (latitude 2903'10" Sul, longitude 53050'44" Oeste, altitude $465 \mathrm{~m}$ ).

A área experimental foi utilizada durante 13 anos em sistema integrado de produção de soja e pastagem de inverno, composta de azevém-anual semeado em 4/5/2005 (25 kg de sementes/ha) em mistura com aveia-preta (100 kg de sementes/ha), em semeadura direta. A adubação utilizada na semeadura foi de $300 \mathrm{~kg} / \mathrm{ha}$ de superfosfato simples e cobertura única de nitrogênio $(\mathrm{N})$ na forma de uréia, em $8 / 6 / 2005$, na quantidade de $45 \mathrm{~kg} / \mathrm{ha}$.

O solo é classificado como Latossolo Vermelho Distroférrico (Embrapa, 1999), de coloração vermelho-escura e textura muito argilosa $(0,54 \mathrm{~kg} / \mathrm{kg}$ de argila, $0,17 \mathrm{~kg} / \mathrm{kg}$ de silte, $0,29 \mathrm{~kg} / \mathrm{kg}$ de areia, na camada de $0-20 \mathrm{~cm}$ ), profundo, bem drenado, com relevo suave ondulado (Streck et al., 2002). O clima predominante, segundo a classificação de Köppen, é o subtropical úmido (Cfa).

A área experimental foi constituída de 12 piquetes com áreas ajustadas conforme os tratamentos propostos, totalizando 22,5 ha, manejados visando manter as alturas do pasto preestabelecidas $(10,20,30,40 \mathrm{~cm})$, o que possibilitou aos animais adaptar às estruturas do pasto durante os 131 dias de pastejo.

O delineamento experimental adotado foi de blocos completos casualizados com três repetições de campo. Os tratamentos foram obtidos por meio de lotação contínua e carga animal variável, pela técnica "put-and-take" (Mott \& Lucas, 1952), utilizando-se três animais avaliadores por unidade experimental para as observações comportamentais. Os animais utilizados foram bovinos de corte provenientes de cruzamento industrial, com massa corporal média de $260 \mathrm{~kg}$ e aproximadamente 1 ano de idade. Os animais foram identificados nas unidades experimentais por meio de suas características morfológicas e brincos plásticos numerados.

As avaliações foram realizadas por observação direta, do nascer ao pôr-do-sol, de modo que os registros de comportamento de pastejo foram feitos em três datas de avaliação (7/9, 9/10, 30/10), duas no estádio vegetativo e uma no estádio reprodutivo. A equipe de trabalho, previamente treinada, foi formada por três observadores por bloco, com binóculos e posicionados externamente a área experimental, a fim de evitar interferência no comportamento animal. O tempo de pastejo foi obtido pelo método direto de observação visual (Penning \& Rutter, 2004), registrando-se a atividade de maior ocorrência ao final de cada intervalo de 10 minutos, incluindo também o tempo destinado a outras atividades e à atividade de ruminação. $\mathrm{O}$ pastejo representou as atividades de procura, de preensão, manipulação e mastigação da forragem.

O tempo necessário para procura e utilização de dez estações alimentares correspondeu ao tempo necessário para o animal alcançar, sem mover suas patas dianteiras, um semicírculo hipotético disponível a sua frente, considerado estação alimentar (Ruyle \& Dwyer, 1985). Cronômetros foram usados conjuntamente às observações visuais. $\mathrm{O}$ número de passos dos animais em cada dez estações 
alimentares foi obtido por meio de observação visual, arma zenando os dados em contadores mecânicos.

A taxa de bocado foi considerada o tempo gasto pelos animais para a realização de 20 bocados, registrados por cronômetro (Penning \& Rutter, 2004). Essas observações foram usadas no cálculo das variáveis: tempo de permanência na estação alimentar, expresso em segundos; número de passos entre estações alimentares; e número de bocado por minuto (taxa de bocado), considerando os valores médios dos três animais avaliadores. Os resultados dessas observações foram registrados em seis ocasiões durante o dia (três avaliações durante a manhã e três à tarde) e usados para determinar: o número total de bocados, produto entre taxa de bocado e tempo de pastejo; o número total de estações alimentares, quociente entre tempo de pastejo e tempo de permanência na estação alimentar; o número total de passos, produto entre o número total de estações alimentares e número de passos entre estações alimentares; e o número de bocados por estação alimentar, quociente entre número de bocados diários pelo número de estações alimentares diárias.

A caracterização da estrutura do pasto foi realizada nos dias 8/9, 29/9 e 29/10/2005. A altura do pasto foi medida com auxílio de um bastão graduado (sward stick - Barthram, 1985), cujo marcador em acrílico transparente desliza por uma régua marcando a distância entre o topo da superfície do pasto (lâmina foliar mais elevada) e a superfície do solo. Os pontos de amostragem foram definidos de forma aleatória, totalizando 100 leituras de altura por unidade experimental.

O valor médio das alturas medidas em cada potreiro foi utilizado como variável independente em equações de regressão linear relacionando-as ao valor de massa de forragem real, avaliada com cinco amostras cortadas a cada 30 dias, segundo metodologia utilizada por Aguinaga (2006).

Nas amostras coletadas para quantificação da massa de forragem real, fez-se a separação manual dos componentes estruturais do pasto nas frações lâmina foliar, colmo + bainha foliar, inflorescência e material senescente. Depois de separado, esse material foi colocado em sacos de papel, identificado e levado à estufa com circulação de ar forçada a $65^{\circ} \mathrm{C}$ até atingir peso constante.

A oferta de forragem foi expressa como a quantidade de massa de forragem dividida pela carga animal nas datas de avaliação de comportamento, expressa em kg de matéria seca de forragem por hectare/kg de peso vivo/dia (Sollenberg et al., 2005).

Os dados foram submetidos à análise de variância e ao teste F a 5\% de significância. Quando detectadas diferenças entre as alturas de manejo $(\mathrm{P}<0,05)$, as médias foram comparadas pelo teste $\mathrm{t}$ (Student) ao mesmo nível de significância, utilizando-se o procedimento Mixed do pacote estatístico SAS, versão 8.2 (SAS, 2001). Foram realizadas análises de regressão até terceira ordem, conforme o modelo

$$
\hat{\mathrm{Y}} \mathrm{ij}=\beta 0+\mathrm{b} 1 \mathrm{Ai}+\mathrm{b} 2 \mathrm{Ai} 2+\mathrm{b} 3 \mathrm{Ai} 3+\gamma(\mathrm{i}, \mathrm{j})+\varepsilon(\mathrm{i}, \mathrm{j}),
$$

em que: $\hat{\mathrm{Y}}=$ variável dependente; $\beta 0=$ intercepto da regressão; $\mathrm{A}$ = variável independente; $\mathrm{b} 1$ = coeficiente linear de regressão da variável Y relacionado à variável independente; b2 = coeficiente quadrático de regressão da variável Y relacionado à variável independente; b3 = coeficiente cúbico de regressão da variável Y relacionado à variável independente; $\gamma=$ desvios da regressão e $\varepsilon=$ erro aleatório residual. Análises de regressão foram realizadas com o auxílio do software estatístico Sigma Plot 2004 v.9.0 para Windows.

$\mathrm{O}$ modelo matemático geral referente à análise das variáveis estudadas foi representado por:

$$
Y_{i k j}=\mu+T_{i}+\beta_{k}+(T \beta)_{i k}+E_{j}+(T E)_{i j}+\varepsilon_{i k j},
$$
em que $\mathrm{Y}_{\mathrm{ikj}}=$ variáveis dependentes; $\mu$ = média de todas as observações; $\mathrm{T}_{\mathrm{i}}=$ efeito das alturas do pasto (tratamentos); $\beta_{\mathrm{k}}=$ efeito do k-ésimo bloco; $(\mathrm{T} \beta)_{\mathrm{ik}}=$ efeito da interação alturas de pasto $\times$ blocos (erro a); $\mathrm{E}_{\mathrm{j}}=$ efeito do j-ésimo estádio fenológico do pasto; $(\mathrm{TP})_{\mathrm{ij}}=$ interação alturas de pasto $\times$ estádios fenológicos; e $\varepsilon_{\mathrm{ikj}}=$ erro experimental residual (erro b).

\section{Resultados e Discussão}

As médias de alturas do pasto no estádio vegetativo foram próximas das alturas preestabelecidas, o que determinou distintas estruturas do pasto.No estádio reprodutivo, as médias das alturas do pasto foram pouco superiores às alturas do pasto pretendidas, especialmente nas alturas de 10 e $20 \mathrm{~cm}$, em decorrência da maior dificuldade de manejo do pasto nessa fase fenológica (Figura 1).

As alturas de manejo do pasto propostas foram condicionadas pelas intensidades de pastejo, assim, a elevação na altura do pasto foi ocasionada pela aplicação de menor carga animal $\left(\hat{\mathrm{Y}}=1325,76-18,87 \mathrm{x} ; \mathrm{R}^{2}=0,9007 ; \mathrm{P}=0,0028\right.$; $\mathrm{CV}=39,51 \%$ ), que variou de 354 a $1173 \pm 80,1 \mathrm{~kg}$ de peso vivo/ha nas altura de 40 e $10 \mathrm{~cm}$, respectivamente. No entanto, não houve interação altura do pasto $\times$ estádio fenológico para a carga animal $(\mathrm{P}>0,05)$.

A massa de forragem aumentou linearmente com a elevação da altura de manejo do pasto $(\hat{\mathrm{Y}}=339,84+112,23 \mathrm{x}$; $\left.\mathrm{R}^{2}=0,9699 ; \mathrm{P}<0,0001 ; \mathrm{CV}=6,30 \%\right)$ e variou $2.112 \mathrm{a}$ $4.961 \pm 84,1 \mathrm{~kg} / \mathrm{ha}$ de MS, respectivamente, da menor altura para a maior altura de manejo do pasto. Não houve interação 


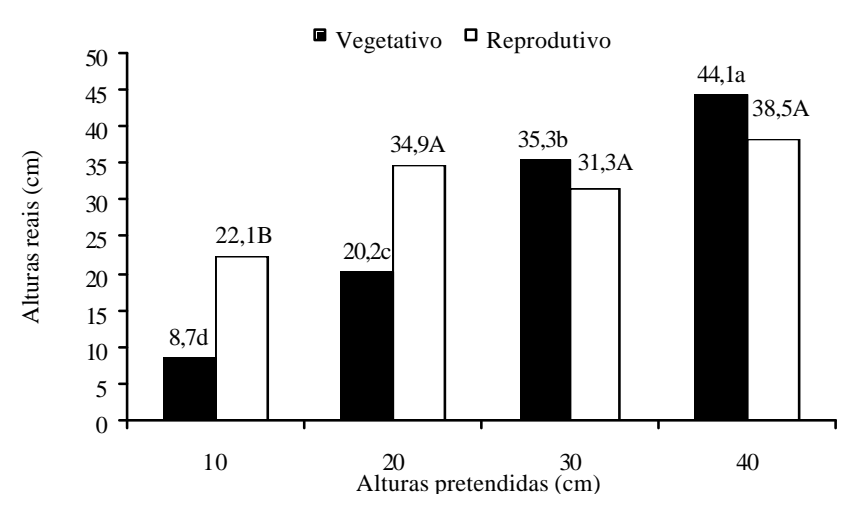

Figura 1 - Relação entre a altura do pasto pretendida e a altura do pasto avaliada em pastagem de azevém anual e aveia preta.

Médias das avaliações nos estádios vegetativo e reprodutivo. Médias seguidas das mesmas letras não diferem pelo teste $t$ de Student a 5\%. Letras minúsculas comparam as alturas do pasto no estádio vegetativo e as maiúsculas, alturas do pasto do estádio reprodutivo.

alturas $\times$ estádio fenológico do pasto $(\mathrm{P}>0,05)$ para a quantidade de massa de forragem.

A massa de lâminas foliares $(\hat{\mathrm{Y}}=471,23+13,73 \mathrm{x}$; $\left.\mathrm{R}^{2}=0,7954 ; \mathrm{P}<0,0001 ; \mathrm{CV}=12,43 \%\right)$ e a massa de colmo + bainha $\left(\hat{\mathrm{Y}}=-325,13+71,49 \mathrm{x} ; \mathrm{R}^{2}=0,9909 ; \mathrm{P}<0,0001\right.$; $\mathrm{CV}=6,41 \%$ ) sofreram interação altura do pasto $\times$ estádio fenológico. Essas variáveis se ajustaram ao modelo de regressão linear no estádio vegetativo, o que comprova aumento na participação desses componentes na estrutura do pasto com o aumento das alturas testadas. No estádio reprodutivo, essas variáveis não se ajustaram a nenhum modelo de regressão e apresentaram médias de $185,67 \pm 33,51$ e $1.300,64 \pm 64,12 \mathrm{~kg} / \mathrm{ha}$ de MS, respectivamente. A massa de material senescente $(P=0,0003)$ e a massa de inflorescências $(\mathrm{P}=0,0110)$ diferiram entre os estádios fenológicos avaliados e apresentaram aumentos de 756 para $1.531 \pm 94,1 \mathrm{~kg} / \mathrm{ha}$ de MS e de 291 para $759 \pm$ $91,9 \mathrm{~kg} / \mathrm{ha}$ de MS, respectivamente, no entanto, não houve interações altura $\times$ estádio fenológico $(\mathrm{P}>0,05)$.

A oferta de forragem aumentou linearmente com a altura do pasto, refletindo o efeito da altura sobre a quantidade de alimento disponível para os animais $\hat{\mathrm{Y}}=-4,27+0,38 \mathrm{x}$; $\left.\mathrm{R}^{2}=0,6366 ; \mathrm{P}<0,0001 ; \mathrm{CV}=48,43 \%\right)$. No entanto, não houve interação altura do pasto $\times$ estádio fenológico $(\mathrm{P}>0,05)$ para a oferta de forragem. A amplitude dos valores de oferta de forragem variou de 1,7 a $14,4 \pm 0,8 \mathrm{~kg} / \mathrm{ha} \mathrm{de} \mathrm{MS} / \mathrm{kg}$ de $\mathrm{PV} /$ dia entre as alturas de 10 e $40 \mathrm{~cm}$, respectivamente.

Com o aumento das alturas de manejo, os animais reduziram a taxa de bocado (Figura 2), que não teve efeito da interação altura $\times$ estádio $(\mathrm{P}>0,05)$.
Conforme descrito por Carvalho (1997), a taxa de bocado apresenta-se inversa e negativamente relacionada à abundância de pasto. Segundo esse autor, o aumento da quantidade de forragem disponível e da massa do bocado determina maior exigência dos processos de mastigação e de manipulação da forragem capturada, o que leva a maior intervalo de bocados. A taxa de bocado apresentou correlação negativa com a massa de forragem $(r=-0,63 ; \mathrm{P}<0,0001)$, o que indica preensão de maior quantidade de forragem a cada bocado, reduzindo a taxa de bocado.

A amplitude dos valores médios obtidos foi de 43,7 $(10 \mathrm{~cm}$ de altura) a 24,6 $\pm 3,8$ bocado/minuto (40 cm de altura). Sarmento (2003), em pastos de Brachiaria brizantha cv. Marandu manejados em alturas de 10,20,30 e $40 \mathrm{~cm}$, obteve taxas de bocado semelhantes, variando de 17,7 a 51,3 bocado/minuto para as alturas de $40 \mathrm{~cm}$ e $10 \mathrm{~cm}$, respectivamente. Entre os estádios avaliados, essa variável apresentou diferença significativa $(\mathrm{P}=0,0002)$, com diminuição do estádio vegetativo para o estádio reprodutivo(37,5 para $27,7 \pm 2,0$ bocados/minuto). O aumento do intervalo de bocados seria resultado do esforço na colheita de menor quantidade de folhas disponíveis nos perfilhos reprodutivos, uma vez que as folhas, além de estarem em mais baixa disponibilidade, se encontram distanciadas pelo aumento dos entrenós dos colmos, dificultando sua captura (Carvalho et al., 2001).

Houve interação altura $\times$ estádio fenológico do pasto $(\mathrm{P}=0,0208)$ para o tempo de permanência na estação alimentar. Observou-se aumento lineardo tempo de permanência na estação alimentar com o aumento da altura do pasto no estádio vegetativo (Figura 3 ).

No estádio reprodutivo, a média do tempo de exploração da estação alimentar foi de $6,9 \pm 0,3$ segundos e não se

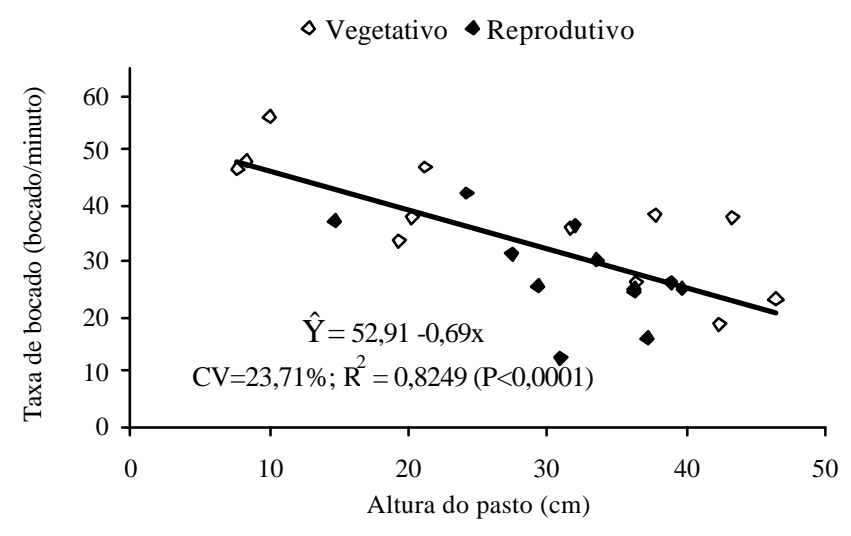

Figura 2 - Relação entre a taxa de bocados e a altura de manejo do pasto em pastagem de azevém-anual e aveia-preta nos estádios vegetativo e reprodutivo. 


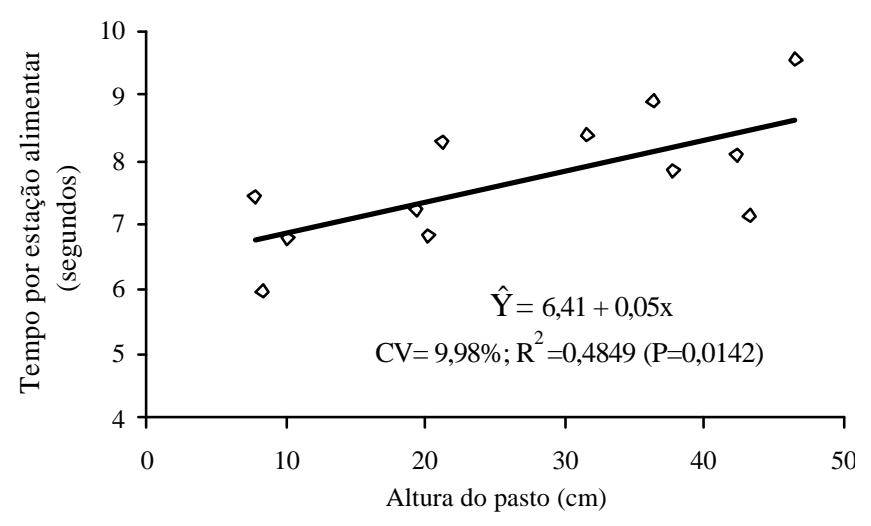

Figura 3 - Relação entre o tempo de permanência na estação alimentar e a altura de manejo do pasto em pastagem de azevém-anual e aveia-preta no estádio vegetativo.

ajustou a nenhum modelo de regressão. Essa variável apresentou correlação positiva com a oferta de lâminas foliares $(\mathrm{r}=0,50 ; \mathrm{P}=0,0019)$. Os resultados deste experimento corroboram os obtidos por Carvalho et al. (1999), que afirmaram que o tempo de permanência na estação alimentar está diretamente relacionado à abundância de forragem. Segundo esses autores, quanto maior a oferta de forragem na estação alimentar, maior o tempo de permanência dos animais. $\mathrm{O}$ animal permanece na estação alimentar até que o ponto de abandono é atingido. A partir desse instante, a relação custo-benefício em continuar a explorar o local de alimentação torna-se desinteressante. Resultados semelhantes foram reportados por Palhano et al. (2006), que submeteram novilhas holandesas a cinco alturas em uma pastagem de capim-mombaça Panicum maximum cv. Mombaça) e observaram que, com o aumento da altura do pasto, os animais passaram a visitar menor número de estações alimentares.

O número de bocado por estação alimentar diminuiu de 2,8 a $4,7 \pm 0,4$ da maior para a menor altura de pastejo, respectivamente, ajustando-se ao modelo de regressão linear. Não houve interação altura $\times$ estádio avaliado ( $\mathrm{P}>0,05)$ para o número de bocado (Figura 4).

Esse comportamento dos animais pode ser explicado pela maior disponibilidade de forragem nas estações alimentares de pasto com maior altura. Segundo Carvalho et al. (2001), essa condição possibilita maior intervalo de um bocado a outro em resposta ao maior volume de forragem apreendida por bocado. Resultados contrastantes foram obtidos por Palhano et al. (2006), entre 6 e 10 bocados por estação alimentar, em estruturas de pasto variando de 60 a $140 \mathrm{~cm}$ de altura.

O aumento na massa de material senescente também influenciou a diminuição do número de bocado por estação

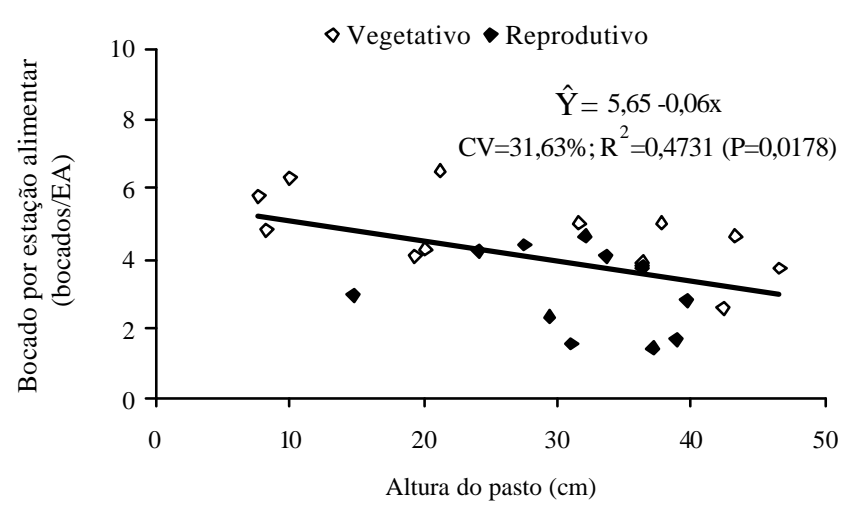

Figura 4 - Relação entre altura do pasto e número de bocado por estação alimentar em pastagem de azevém-anual e aveia-preta nos estádios vegetativo e reprodutivo.

alimentar, tendo em vista a correlação negativa com esse componente do pasto $(\mathrm{r}=-0,78 ; \mathrm{P}<0,0001)$. Esse aumento da quantidade traria dificuldade na seleção da dieta dentro de uma mesma estação alimentar nos pastos de maior altura, considerando que as lâminas foliares encontram-se entremeadas na grande quantidade de material morto, resultando em maior intervalo de tempo de um bocado a outro.

O número de passos entre estações alimentares variou de 1,36 a 1,53 $\pm 0,1$ entre a menor e maior altura de manejo do pasto, mas não teve influência significativa da altura $(\mathrm{P}>0,05)$. No entanto, a oferta de lâminas foliares correlacionou-se positivamente com essa variável $(\mathrm{r}=0,51$; $\mathrm{P}=0,0115)$, o que está de acordo com o modelo proposto por Carvalho \& Moraes (2005). O deslocamento entre estações alimentares foi maior em situação de abundância de forragem. De acordo com Carvalho \& Moraes (2005), este maior deslocamento com elevada massa de forragem é permitido pela colheita de bocados com alta quantidade de forragem, assim como os animais procuram ser eficientes e não se deslocam se não estiverem executando qualquer atividade, portanto, quanto maior o último bolo colhido a ser mastigado, maior o tempo para escolha e deslocamento.

Baggio et al. (2008) demonstraram que, com a diminuição da altura do pasto, aumenta o tempo de pastejo, que varia de 459 a $380 \pm 37,1$ minutos, respectivamente, para as alturas de 10 e $40 \mathrm{~cm}$. Como conseqüência da combinação destas estratégias de pastejo, constatou-se elevação no número total de bocado em situações de baixa disponibilidade de forragem (Figura 5), com valores variando entre 8.960 a $20.139 \pm 2.018,1$ bocados para as alturas de 40 e $10 \mathrm{~cm}$, respectivamente. Não houve interação altura do pasto $x$ estádio avaliado $(\mathrm{P}>0,05)$ para essa variável.

$\mathrm{O}$ número total de bocado apresentou correlação nega tiva com a massa de forragem $(\mathrm{r}=-0,78 ; \mathrm{P}<0,0001)$. A 
redução da quantidade de massa de forragem, associada à diminuição da altura do pasto, resultou em aumento no número total de bocado. A freqüência média, bem como o número total de bocado realizado por animais em pastejo, está relacionada a características inerentes à estrutura do pasto, mas também possui relação com variações nos padrões da principal determinante da quantidade de alimento consumida pelo animal em pastejo, a massa do bocado (Cosgrove, 1997). Isto decorre do fato de que, quanto menor a altura do pasto, menos efetiva é a capacidade dos animais em ampliar a quantidade de forragem apreendida (Prache \& Peyraud, 2001). Dessa forma, os animais mantidos em pastos de menor altura necessitaram aumentar o tempo de pastejo (Baggio et al., 2008) e a taxa de bocado, além do número de bocado por estação alimentar e o número de bocado diário visando compensar a menor massa apreendida por bocado e manter níveis de consumo satisfatórios. Conforme Carvalho et al. (2001), a apreensão de forragem no bocado é um processo que, não raro, pode atingir em torno de 35.000 ações diárias, uma vez que os animais freqüentemente pastejam ao ritmo de um bocado a cada 1 a 2 segundos.

Entre os estádios avaliados houve diferença significativa para o número de bocados por estação alimentar $(\mathrm{P}=0,0011)$ bem como para o número total de bocado $(\mathrm{P}=0,0261)$. Os valores médios obtidos foram de 4,7 e $3,1 \pm 0,3$ bocados por estação alimentar e 14.926 e $12.651 \pm 1.091,9$ bocados/dia nos estádios vegetativo e reprodutivo, respectivamente. Esse padrão de resposta pode ser explicado pelo aumento da proporção de material senescente e inflorescências na estrutura do pasto e pela redução da quantidade de lâminas foliares. Essas alterações também podem levar a modificações na qualidade da forragem ingerida, o dificultando a procura por bocados

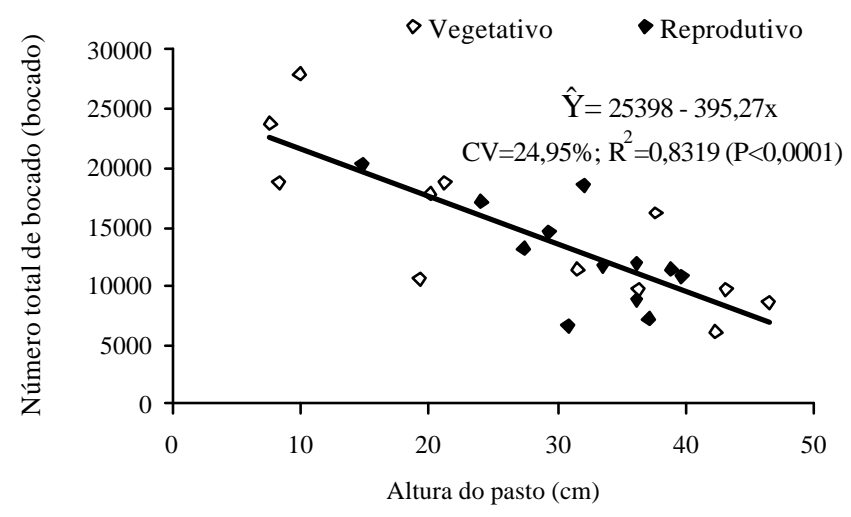

Figura 5 - Relação entre a altura do pasto e o número total de bocado em pastagem de azevém-anual e aveia-preta nos estádios vegetativo e reprodutivo. potenciais dentro de uma estação alimentar e, conseqüentemente, ao longo do período diurno de pastejo.

O número de estações alimentares não foi influenciado pela altura de manejo do pasto $(\mathrm{P}>0,05)$, no entanto, verificou-se correlação negativa com a massa de lâminas foliares ( $r=-0,63 ; P=0,0009$ ) (Figura 6). Com a diminuição da massa de lâminas foliares, houve aumento no número total de estações alimentares. Ogura et al. (2004) mencionaram que o aumento no número de estações alimentares é relacionado ao menor tempo de permanência, bem como à menor movimentação entre estações alimentares sucessivas.

As estações alimentares de pastos baixos, com conseqüente menor participação do componente lâmina foliar, apresentaram tempo de permanênciareduzido. As estações alimentares com baixa oferta de forragem rapidamente atingem o ponto de abandono e os animais se deslocam para estabelecerem nova estação alimentar (Carvalho \& Moraes, 2005). Nessas situações os animais necessitaram aumentar o número total de estações alimentares diárias a fim de manter a taxa de consumo de forragem. Houve efeito dos estádios avaliados $(\mathrm{P}=0,0180)$ aumentando de 3.123 para $4.354 \pm 334,7$ estações alimentares do estádio vegetativo para o reprodutivo, respectivamente, fato as sociado à menor disponibilidade do componente lâmina foliar e ao aumento da participação de material senescente e das inflorescências com o avançar da fenologia do pasto.

Quanto ao deslocamento dos animais na pastagem, não foi verificada influência da altura do pasto sobre o número total de passos $(\mathrm{P}>0,05)$. Entretanto, essa variável apresentou correlação com a massa de lâminas foliares ( $\mathrm{r}=-0,57 ; \mathrm{P}=0,0033)$, demonstrando aumento do número total de passos com a diminuição desse componente do pasto (Figura 7).

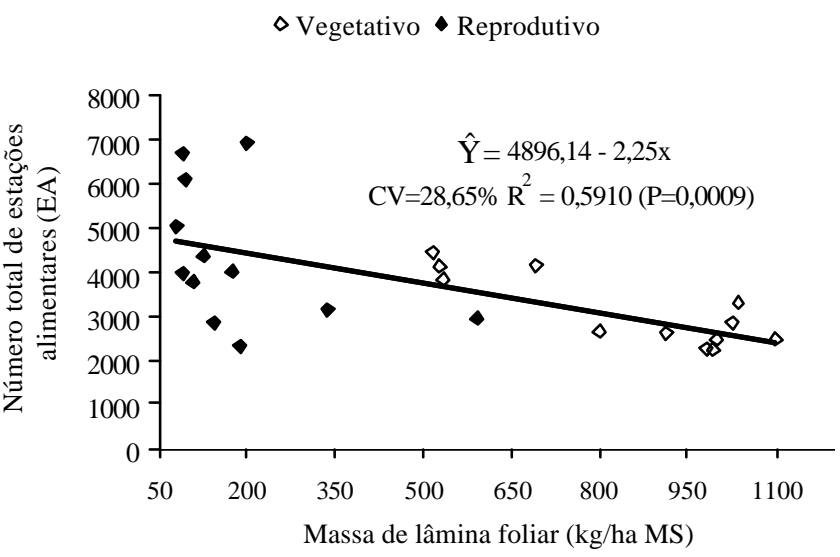

Figura 6 - Relação entre o número total de estações alimentares e a massa de lâmina foliar em pastagem de azevém-anual e aveia-preta nos estádios vegetativo e reprodutivo. 
$\diamond$ Vegetativo $\bullet$ Reprodutivo

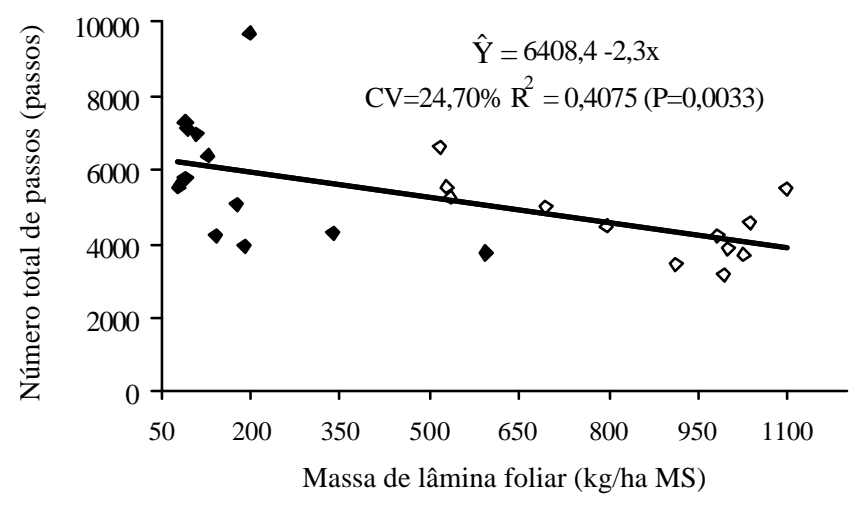

Figura 7 - Relação entre o número total de passos e a massa de lâmina foliar em pastagem de azevém-anual e aveiapreta nos estádios vegetativo e reprodutivo.

Segundo Carvalho \& Moraes (2005), em situações de estrutura do pasto não-limitante, a forragem é abundante e folhosa, o deslocamento entre estações alimentares pode ser mais longo, porém, a quantidade de deslocamento total é menor que em situações limitantes de forragem disponível. Nessas situações, a alta taxa de consumo permite ao animal alocar mais tempo na procura de estações alimentares preferidas, enquanto caminham maiores distâncias mastigando bocados de alta massa (Roguet et al., 1998). Esse comportamento está de acordo com as observações de Palhano et al. (2006) de que, apesar do aumento na distância percorrida entre estações alimentares com o aumento da altura do pasto, os animais apresentaram menor deslocamento total.

\section{Conclusões}

Os animais intensificam os processos de busca e apreensão da forragem em pastos manejados com baixa altura e menor massa de forragem. Há aumento da taxa de bocado, do número de bocado por estação alimentar, do número total de bocado e do número de estação alimentar visitada e redução do tempo de permanência na estação alimentar e este padrão de resposta resulta em menor deslocamento entre estações alimentares, porém a quantidade de deslocamento total é maior. Os animais modificam os padrões de captura por forragem no estádio reprodutivo, diminuindo a taxa de bocados, o número de bocado por estação alimentar e o número total de bocados e aumentando o número total de estações alimentares em relação ao estádio vegetativo.

\section{Agradecimentos}

Aos membros do Grupo de Pesquisa em Ecologia do Pastejo, da Agropecuária Cerro Coroado e do CNPq.

\section{Literatura Citada}

AgUinagA, A.A.Q.; CARVALHO, P.C.F.; ANGHINONI, I. et al. Produção de novillos superprecoces em pastagem de aveia e azevém submetida a diferentes alturas de manejo. Revista Brasileira de Zootecnia, v.35, p. 1765-1773, 2006.

BAGGIO, C.; CARVALHO, P.C.F.; SILVA, J.L.S. et al. Padrões de uso do tempo por novilhos em pastagem consorciada de azevém anual e aveia-preta Revista Brasileira de Zootecnia, v.37, n.11, p. 1912-1918, 2008.

BARTHRAM, G.T. Experimental techniques: the HFRO sward stick. Aberdeen: Hill Farming Research Organization/Biennial Report. 1985. p.29-30.

CONTE, O.; LEVIEN, R.; TREIN, C.R. et al. Demanda de tração em haste sulcadora na integração lavoura-pecuária com diferentes pressões de pastejo e a sua relação com o estado de compactação do solo. Engenharia Agrícola, v.27, n.1, p.222-228, 2007.

CARVALHO, P.C.F. A estrutura da pastagem e o comportamento ingestivo de ruminantes em pastejo. In: SIMPÓSIO SOBRE AVALIAÇÃO DE PASTAGENS COM ANIMAIS, 2., 1997, Maringá. Anais... Maringá: Universidade Estadual de Maringá. 1997, p.25-52.

CARVALHO, P.C.F.; MORAES, A. Comportamento ingestivo de ruminantes: bases para o manejo sustentável do pasto. In: MANEJO SUSTENTÁVEL EM PASTAGEM, 1., 2005, Maringá. Anais... Maringá: Universidade Estadual de Maringá, 2005. p.1-20.

CARVALHO, P.C.F.; PRACHE, S.; DAMASCENO, J.C.O. Processo de pastejo: desafios da procura e apreensão da forragem pelo herbívoro. In: REUNIÃO ANUAL DA SOCIEDADE BRASILEIRA DE ZOOTECNIA, 36., Porto Alegre, 1999. Anais... Porto Alegre, 1999. p.253-268.

CARVALHO, P.C.F.; RIBEIRO FILHO, H.M.N.; POLI, C.H.E.C. et al. Importância da estrutura da pastagem na ingestão e seleção de dietas pelo animal em pastejo. In: REUNIÃO ANUAL DA SOCIEDADE BRASILEIRA DE ZOOTECNIA, 38., 2001, Piracicaba. Anais... Piracicaba: Sociedade Brasileira de Zootecnia, 2001. p.853-871.

CARVALHO, P.C.F.; ANGHINONI, I.; MORAES, A. et al. O estado da arte em integração lavoura-pecuária.. In: GOTTSCHALL C.S.; SILVA, J.L.S.; RODRIGUES, N.C. (Eds.). Produção animal: mitos, pesquia e adoção de tecnologia. Canoas: Editora da ULBRA, 2005. p.7-44.

COSGROVE, G.P. Grazing behavior and forage intake. In: INTERNATIONAL SYMPOSIUM ON ANIMAL PRODUCTION UNDER GRAZING, 1997, Viçosa, MG. Anais... Viçosa, MG: Universidade Federal de Viçosa, 1997. p.59-80.

EMPRESA BRASILEIRA DE PESQUISA AGROPECUÁRIA EMBRAPA. Centro Nacional de Pesquisa de Solos. Sistema brasileiro de classificação de solos. Rio de Janeiro, 1999. 412p.

MOTT, G.O.; LUCAS, H.L. The design, conduct, and interpretation of grazing trials on cultivated and improved pastures. In: INTERNATIONAL GRASSLAND CONGRESS, 6., 1952, Pensylvania. Proceedings... Pensylvania: 1952. p.1380-1385.

OGURA, S.; SEKINO, R.; HIRATA, M. Foraging behaviour of cattle in a bahiagrass (Paspalum notatum Flugge) pasture: investigation at a feeding station scale. Grassland Science, v.50, p.147-153.

PALHANO, A.L.S.; CARVALHO, P.C.F.; DITTRICH, J.R. et al. Padrões de deslocamento e procura por forragem de novilhas leiteiras em pastagem de capim-mombaça. Revista Brasileira de Zootecnia, v.35, p.2253-2259, 2006. 
PENNING, P.D.; RUTTER, S.M. Ingestive behavior. In: THE BRITISH GRASSLAND SOCIETY (Ed.). Herbage intake handbook. 2.ed. Reading: British, 2004. p.151-175.

PRACHE, S.; PEYRAUD, J. Foraging: behaviour and intake in temperate cultivated grassland. In: INTERNATIONAL GRASSLAND CONGRESS, 19., 2001, São Pedro. Proceedings... São Pedro, 2001. p.309-319.

ROGUET, C.; DUMONT, B.; PRACHE, S. Selection and use of feeding sites and feeding station by herbivores: A review. Annales de Zootechnie, v.47, p.225-244, 1998.

RUYLE, G.B.; DWYER, D.D. Feeding stations of sheep as an indicator of diminished forage supply. Journal of Animal Science, v.61, p.335-353, 1985.

SARMENTO, D.O.L. Comportamento ingestivo de bovinos em pastagens de capim Marandu submetidos a regimes de lotação contínua. 2003. 76f. Dissertação (Mestrado em
Agronomia) - Universidade Federal de São Paulo, Escola Superior de Agricultura "Luiz de Queiroz", Piracicaba, 2003.

STATISTICAL ANALYSIS SYSTEM - SAS. Statistical analysis system user's guide. Version 8.2 Cary: Statistical analysis System Institute, 2001. (CD-ROM).

SOLLENBERG, L.E.; MOORE, J.E.; ALLEN, V.G. et al. Reporting forage allowance in grazing experiments. Crop Science Society of America, v.45, p.896-900, 2005.

STRECK, E.V.; KÄMPF, N.; DALMOLIN, R.S.D. Principais classes de solo identificadas no Rio Grande do Sul. In STRECK, E.V.; KÄMPF, N.; DALMOLIN, R.S.D (Eds.) Solos do Rio Grande do Sul. 1.ed. Porto Alegre, 2002. p.23-50.

STUTH, J. Foraging behaviour. In: HEITSCHMIDT, R.K., STUTH, J. (Eds.). Grazing management: an ecological perspective. Oregon: Timber Press, 1991. p.85-108. 